REVISTA DE GEOCIÊNCIAS DO NORDESTE

Northeast Geosciences Journal

v. $7, \mathrm{n}^{\mathrm{o}} 1(2021)$

ISSN: $2447-3359$

https://doi.org/10.21680/2447-3359.2021v7n1ID20759

\title{
POTENCIAL ECONÔMICO DO MUNICÍPIO DE GOIANA-PE: EXEMPLO DE DEPÓSITOS ARENOSOS PARA CONSTRUÇÃO CIVIL
}

\section{José Diego Dias Veras ${ }^{1}$; Virgínio Henrique de Miranda Lopes Neumann²; Silvio Roberto de Oliveira $^{3}$}

${ }^{1}$ Mestre em Geociências, Programa de Pós-Graduação em Geociências, Universidade Federal de Pernambuco (UFPE), Recife/PE, Brasil.

ORCID: https://orcid.org/0000-0003-2716-4737

Email: diegodias_ig@hotmail.com

${ }^{2}$ Doutor em Análise de Bacias Sedimentares, Departamento de Geologia, Universidade Federal de Pernambuco (UFPE), Recife/PE, Brasil.

ORCID: $\underline{\text { https://orcid.org/0000-0002-8827-6022 }}$

Email: neumann@ufpe.br

${ }^{3}$ Geólogo, Grupo João Santos/Cimento Nassau, Recife/PE, Brasil.

ORCID: https://orcid.org/0000-0003-1797-8892

Email: sroliveira47@gmail.com

\section{Resumo}

O município de Goiana está localizado no extremo norte do litoral pernambucano limitando-se diretamente com o estado da Paraíba. Está situado ao norte da capital pernambucana (Recife) e inserido no contexto geológico da Bacia Paraíba onde predominam coberturas sedimentares desde o Cretáceo Superior até o recente. A Formação Barreiras abrange consideravelmente uma porção territorial do município. Esta unidade está relacionada a existência de leques aluviais e sistemas fluviais que possivelmente gradavam para sistemas deltaicos e, apresentam uma variação faciológica desde argilitos até conglomerados. A ação do intemperismo e da lixiviação associada sobre as camadas areno-argilosas dessa unidade originou a ocorrência de depósitos arenosos com alto teor de $\mathrm{SiO}_{2}(>95 \%)$ conhecidos como "areias brancas". A espessura destes depósitos varia entre 0,1 e 3 metros e os grãos são bem selecionados e subangulosos. A fração granulométrica predominante é fina a média de acordo com os padrões da Associação Brasileira de Normas Técnicas (ABNT). Considerando todos as características do bem mineral, a qualidade e a composição dos depósitos, as "areias brancas" são consideradas de boa qualidade para a indústria de construção, razão pela qual os estudos e as explorações vêm se intensificando na região.

Palavras-chave: Areias Brancas; Tabuleiros Costeiros; Bacia Paraíba.

\section{ECONOMIC POTENTIAL OF THE GOIANA CITY-PE: SANDY DEPOSITS EXAMPLE FOR CIVIL CONSTRUCTION}

\section{Abstract}

The Goiana City is located at the northern end of the Pernambuco coast, directly bordering the state of Paraíba. It is located to the north of the Pernambuco principal city (Recife) and inserted in the geological context of the Paraíba Basin where sedimentary coverings predominate from the Upper Cretaceous to the recent age. The Barreiras Formation covers a considerable portion of the city. This unit is related to the existence of alluvial fans and fluvial systems that possibly were graded to deltaic systems and, they present a facies variation from clay to conglomerates. The action of weathering and associated leaching on the sandy-clay layers of this unit led to the occurrence of sandy deposits with a high content of $\mathrm{SiO}_{2}(>95 \%)$ known as "white sands". The thickness of these deposits varies between 0.1 and 3 meters and the grains are well selected and subangular. The predominant particle size fraction is fine to medium according to the standards of the Brazilian Association of Technical Standards (ABNT). Considering all the characteristics of the ore, the deposits quality and composition, the "white sands" are considered to be of good quality for the construction industry, which is why studies and explorations have been intensifying in the region.

Keywords: White Sands; Coastal Boards; Paraíba Basin.

POTENCIAL ECONÓMICO DE LA CIUDAD DE GOIANA-PE: EJEMPLO DE DEPÓSITOS ARENOSOS PARA CONSTRUCCIÓN CIVIL

\section{Resumen}

El municipio de Goiana está ubicado en el extremo norte de la costa de Pernambuco, limitándose directamente con el estado de Paraíba. Se ubica al norte de la capital de Pernambuco (Recife) y se inserta en el contexto geológico de la cuenca de Paraíba, donde predominan los revestimientos sedimentarios desde el Cretácico Superior hasta el reciente. La Formación Barreiras cubre una 
porción considerable del municipio. Esta unidad está relacionada con la existencia de abanicos aluviales y sistemas fluviales que posiblemente fueron clasificados para sistemas deltaicos y presentan una variación fisiológica de arcilla a conglomerados. La acción de la meteorización y la lixiviación asociada en las capas arenosas-arcillosas de esta unidad condujeron a la aparición de depósitos arenosos con un alto contenido de $\mathrm{SiO}_{2}$ (> 95\%) conocidos como "arenas blancas". El grosor de estos depósitos varía entre 0,1 y 3 metros y los granos están bien seleccionados y son subangulares. La fracción de tamaño de partícula predominante es de fina a media según los estándares de la Asociación Brasileña de Estándares Técnicos (ABNT). Teniendo en cuenta todas las características del bien mineral, la calidad y la composición de los depósitos, las "arenas blancas" se consideran de buena calidad para la industria de la construcción, por lo que se han intensificado los estudios y exploraciones en la región.

Palabras-clave: Arenas Blancas; Tablas Costeras; Paraíba Cuenca.

\section{INTRODUÇÃO}

O termo areia, designa um material granular, com diâmetro em um intervalo definido ( 2 a $0,06 \mathrm{~mm}$ ), de composição silicática, com predominância do mineral de quartzo, ou de outros minerais, fragmentos de conchas $\left(\mathrm{CaCO}_{3}\right)$ resultantes de desagregação natural ou cominuição de rochas ou de conchas de organismos, mais ou menos cimentadas (DNPM, 2015).

De forma genérica, areia abrange um amplo conjunto de materiais granulares (essencialmente quartzo), com diferentes especificações e usos, tais como: agregados para a construção civil, moldes de fundição, indústrias de transformação (vidros, abrasivos, química, cerâmica, siderurgia, fundição, filttros, cimento, refratários), tratamento de águas e esgotos, minério portador de minerais de interesse econômico, como: monazita (cério e terras-raras), ilmenita (titânio), ouro, cassiterita e outros (Quaresma, 2009).

A produção de areia é um setor básico na cadeia da indústria da construção civil, tem faturamento importante e gera muitos empregos. A atividade econômica de produção de areia caracteriza-se por grandes volumes produzidos. $\mathrm{O}$ transporte responde por cerca de $2 / 3$ do preço final dos produtos, o que impõe a necessidade de produzi-los o mais próximo possível do mercado, que são os aglomerados urbanos (Quaresma, 2009).

A produção de areia para a construção civil está disseminada por todo território nacional. Todos os estados do país possuem alguma mina de areia para construção. No levantamento "Universo da Mineração Brasileira", de 2007, feita com base nos Relatórios Anuais de Lavra, listou 742 lavras de areia. O número de empresas que produz areia é da ordem de 2.000, segundo a ANEPAC (Quaresma, 2009).

O município de Goiana (Pernambuco) apresenta um considerável potencial econômico para tal bem mineral, popularmente chamado de "areia branca". Esse potencial é caracterizado por uma origem sedimentar decorrente do intemperismo da Formação Barreiras, concentrada no litoral pernambucano. Aqui, nós apresentamos características destes depósitos considerando a atividade exploratória desse bem mineral no município de Goiana.

\section{METODOLOGIA}

Este trabalho reflete o agrupamento de algumas informações obtidas em campo através da realização de pesquisas minerais realizadas no município de Goiana com o intuito de identificar reservas do referido bem mineral, areia para construção civil, assim como a obtenção de dados públicos localizados em website da Agência Nacional de Mineração (ANM).

Além do mapeamento geológico realizado na região, os intervalos que contêm o bem mineral foram separados e amostrados para uma melhor classificação. Os referidos intervalos foram submetidos às análises granulométricas (separador granulométrico) e químicas (fluorescência de raios-X).

Algumas dessas informações são de caráter sigiloso (como por exemplo, localização exata de reservas e perfurações), de modo que fica vetada a divulgação destas pelo responsável técnico.

\section{CARACTERIZAÇÃO DO MUNICÍPIO DE GOIANA}

O município de Goiana está localizado na mesorregião Mata e na Microrregião Mata Setentrional do Estado de Pernambuco, limitando-se a norte com o estado da Paraíba, a sul com Itaquitinga, Igarassu, Itapissuma e Itamaracá, a leste com o Oceano Atlântico e a oeste com Condado e Itambé (Figura 1), distando, aproximadamente, $65 \mathrm{~km}$ a norte da capital, cujo acesso é feito pela rodovia pavimentada BR-101.

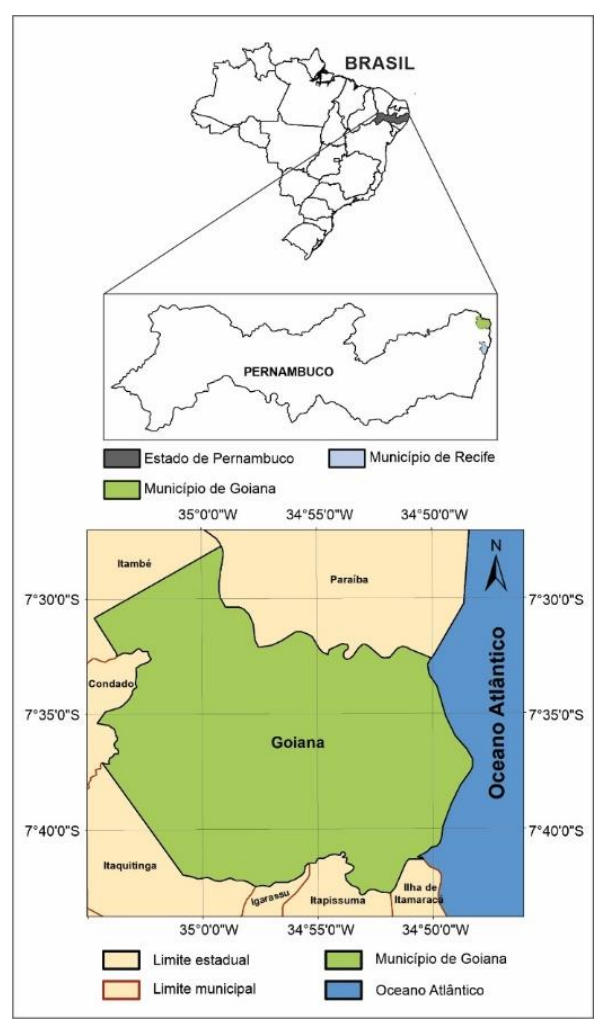

Figura 1 - Localização do município de Goiana no estado de Pernambuco e referência aos seus limites municipais e com o estado da Paraíba. Fonte: autor (2019). 
A área municipal ocupa aproximadamente $500 \mathrm{~km}^{2}$ e representa 0,50\% do Estado de Pernambuco e está inserido nas Folhas SUDENE Itamaracá (SB-25-X-C-VI) e Limoeiro (SB-24Y-C-V) na escala 1:100.000.

Dentre os aspectos fisiográficos, destacam-se: o clima do tipo Tropical Chuvoso; a vegetação do tipo Floresta Subperenefólia, com porções de Floresta Subcaducifólia e cerrado; as águas superficiais inseridas na Bacia Hidrográfica do Rio Goiana, possuindo vários canais distributários, riachos e açudes; e o relevo faz parte predominantemente da unidade dos Tabuleiros Costeiros (CPRM, 2005).

\section{GEOMORFOLOGIA E GEOLOGIA REGIONAL}

A gênese da Bacia Paraíba, como também das bacias sedimentares marginais do atlântico sul, está relacionada à abertura do Oceano Atlântico Sul, que ocorreu a partir da fragmentação do continente Gondwana. A evolução deste processo de rifteamento resultou na formação de bacias de margem passiva, que atualmente representam os principais alvos exploratórios petrolíferos na margem Atlântica do Brasil. A bacia está inserida no contexto regional da Província Borborema. Almeida et al. (1977) definiram o nome para região de dobramentos do nordeste de Brito Neves (1975), situada ao norte do Cráton São Francisco e afetada pela Orogênese Brasiliana.

Oliveira \& Santos (1993) e Santos (1995, 1996), baseando-se no modelo de evolução do tipo colagem tectônica, implantaram o conceito de "terrenos" ou processo de colagem de terrenos tectono-estratigráficos distintos na qual os terrenos da Província Borborema, na evolução pré-cambriana, teriam sido colados durante eventos orogênicos: Cariris Velhos (de idade Greenville) e Brasiliana (Pan-Africana). Esta última teria sido responsável pela justaposição e dispersão dos terrenos (Figura 2).

A Bacia Paraíba foi implantada sob três terrenos distintos da Província Borborema: 1) Terreno Rio Capibaribe representado por ortognaisses paleoproterozoicos (1,97 a 2,12 Ga, NEVES et al., 2006), e pelo ortognaisse Taquaritinga, Mesoproterozoico (1,5 Ga, SÁ et al., 2002). A cobertura, metassedimentar, é composta pelo Complexo Surubim, representado por xistos e gnaisses pelíticos com granada e/ou sillimanita, mármores, quartzitos e rochas calcissilicáticas; 2) Terreno Alto Moxotó - representado por sequências supracrustais metavulcanossedimetares dos complexos Lagoa das Contendas (1,012 $\pm 18 \mathrm{Ma}$, SANTOS et al., 1994 e 1995a) e Sertânia, sequência Caroalina; 3) Terreno Alto Pajeú - principal representante do evento geológico Cariris Velhos, é representado por uma associação metassedimentar intercalada com rochas metavulcânicas e metavulcanoclásticas pertencentes ao Grupo São Caetano. Esses domínios fazem parte da Zona Transversal da Província Borborema que é limitada pelas duas principais zonas de Cisalhamento da região, a Zona de Cisalhamento Pernambuco (ZCPE), a sul, e a Zona de Cisalhamento Patos (ZCPA), a norte.

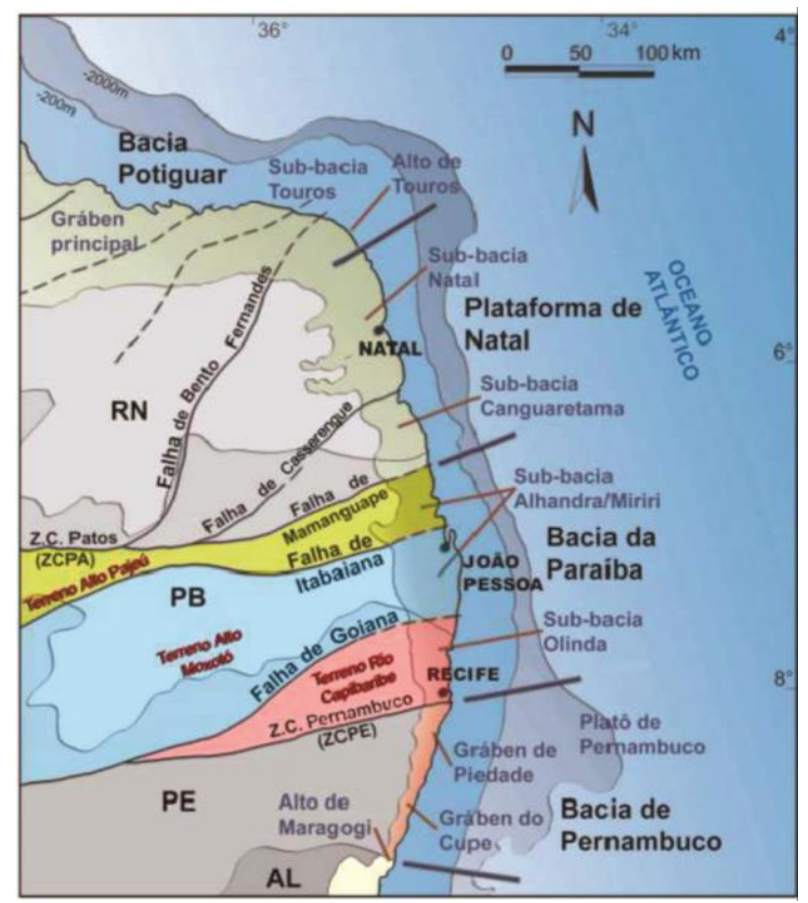

Figura 2 - Subdivisão das bacias marginais da porção oriental do nordeste do Brasil. Em destaque, os terrenos pré-cambrianos que compõem o embasamento da Bacia Paraíba, cujos domínios coincidem com a Zona Transversal do Nordeste, limitada pelas grandes Zonas de Cisalhamento Pernambuco e Patos. Fonte: modificado de Barbosa (2007).

A Bacia Paraíba apresenta seis unidades litoestratigráficas depositadas em diferentes estágios evolutivos do rifte Atlântico Sul (Figura 3). A Formação Beberibe, unidade basal, corresponde a arenitos fluvio-lacustres de idade Santoniana - Campaniana (BEURLEN, 1967a, 1967b, 1967c; MABESOONE; ALHEIROS, 1988; FEIJÓ, 1994; SOUZA, 1998); a Formação Itamaracá, que representa uma sequência transicional, é representada por arenitos calcíferos, margas e calcário siliciclásticos de idade MesoCampaniana-Neo-Maastrichtiana (KEGEL, 1955; LIMA FILHO et al., 1998; BARBOSA et al., 2003; SOUZA 1998, 2006; MOURA, 2007); recobrindo os depósitos transicionais, ocorrem carbonatos de plataforma rasa da Formação Gramame de idade Maastrichtiana (MAURY, 1930; BEURLEN, 1967a, 1967b, 1967c; TINOCO, 1971; MUNIZ, 1993; LIMA \& KOUTSOUKOS, 2002) que formam cobertura estreita, próxima a zona de litoral, de praticamente toda a faixa costeira (BARBOSA, 2007), e da Formação Maria Farinha de idade Daniana, que apresenta ocorrência restrita a linha de litoral na Sub-bacia Olinda (BEURLEN, 1967a, 1967, 1967c; MUNIZ, 1993), ocorrendo ainda, os calcários recifais de idade Eocênica da Formação Tambaba (CORREIA FILHO et al., 2015), depositados sobre uma faixa estreita do litoral na Sub-Bacia Alhandra; e também ocorrem depósitos de natureza continental da Formação Barreiras, que apresenta idade Mioceno-Pleistoceno (ARAI et al., 1988, 1994, 1997; LEITE et al., 1997a, b; BEZERRA, 2014; ROSSETI, 2006). 


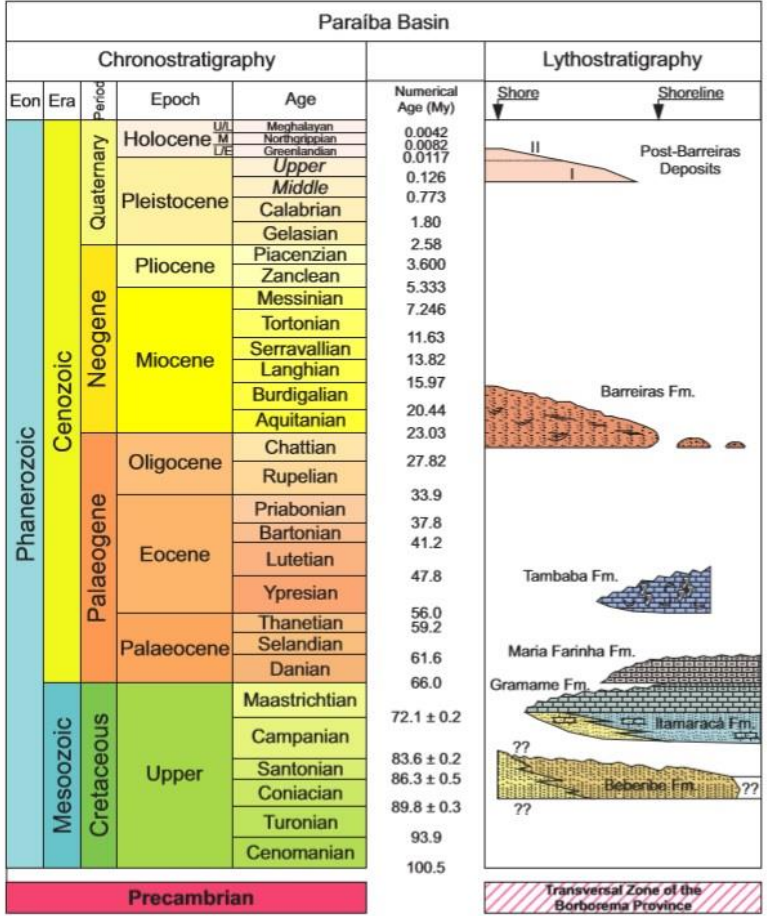

Figura 3 - Carta estratigráfica para a porção emersa da Bacia Paraíba, considerando o registro das unidades nas duas subbacias (norte-sul). Fonte: Correia Filho et al (2015).

$\mathrm{Na}$ faixa costeira do estado de Pernambuco, os tabuleiros costeiros constituem os platôs localizados, dominantemente, no litoral norte do estado, entre a Baixada Litorânea e as áreas do embasamento cristalino. Apresentam superfícies tabulares dissecadas por vales, como o do rio Goiana e de pequenos rios litorâneos, com altitude média na faixa de 50 a $150 \mathrm{~m}$ acima do nível do mar (TORRES \& PFALTZGRAFF, 2014).

\section{RESULTADOS E DISCUSSÕES}

Esse bem mineral ocorre dominantemente nos vales dos principais rios existentes do município, bem como em coberturas coluviais, resultantes do intemperismo e erosão de rochas metamórficas, ocorrendo ainda as areias em coberturas eluviais resultantes do intemperismo de rochas granitoides, e também, intemperismo de rochas sedimentares.

A região está coberta em sua grande maioria por plantação de cana de açúcar, possuindo pequenos trechos com vegetação em estágio de desenvolvimento inicial, pasto, gramíneas, árvores frutíferas (Figura 4A; Figura 4B). Os tabuleiros costeiros são as feições geomorfológicas mais pronunciadas e evidenciadas no relevo da região, os quais são formados decorrente da deposição e erosão da Formação Barreiras, e propiciam a formação dessas reservas minerais.

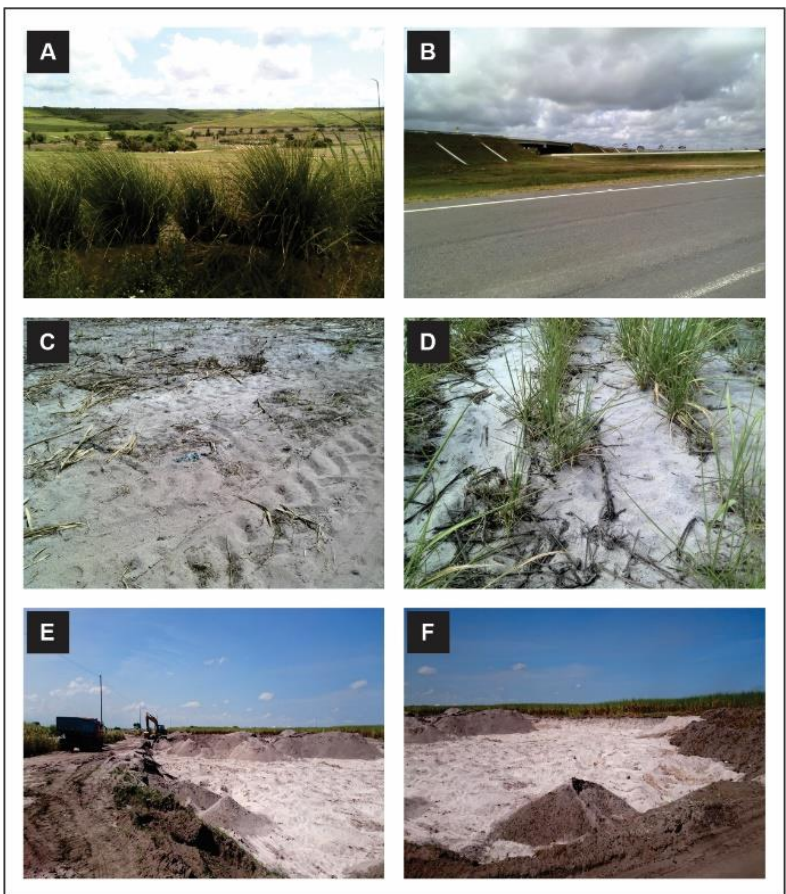

Figura 04 - Fotos da região estudada. A) Fisiografia de tabuleiros e vegetação característica formada pelo cultivo de cana-de-açúcar, gramíneas e árvores frutíferas; B) Acesso da região, favorecida pela rodovia federal BR-101; C) e D) Ocorrência do minério ("areias brancas") em superficie; E) e F) Método de exploração do minério à céu aberto. Fonte: autor (2019).

Com base nas informações obtidas em campo, a ocorrência dos níveis arenosos, conhecidos como "areias brancas", do município de Goiana foram formados, em sua grande maioria, sobre as camadas areno-argilosas da Formação Barreiras (Figura 5), em decorrência do processo de intemperismo químico regional e da lixiviação associada (Figura 4C; Figura 4D). Após esses processos, a Formação Barreiras proporcionou a formação de pequenas bacias (Figura 4E; Figura 4F), as quais são responsáveis por conter tal bem mineral.

Essas bacias referem-se a camadas arenosas - por vezes possuindo capeamento, podendo ser solo ou areia de mesma textura e composição do minério, mas com um teor de matéria orgânica muito mais elevado - predominantemente quartzosas, com grãos bem selecionados, subangulosos, com espessura variando entre 0,10 a 3,00 metros (Figura 7), horizontalizadas e dispostas preferencialmente em tabuleiros planos da região. 


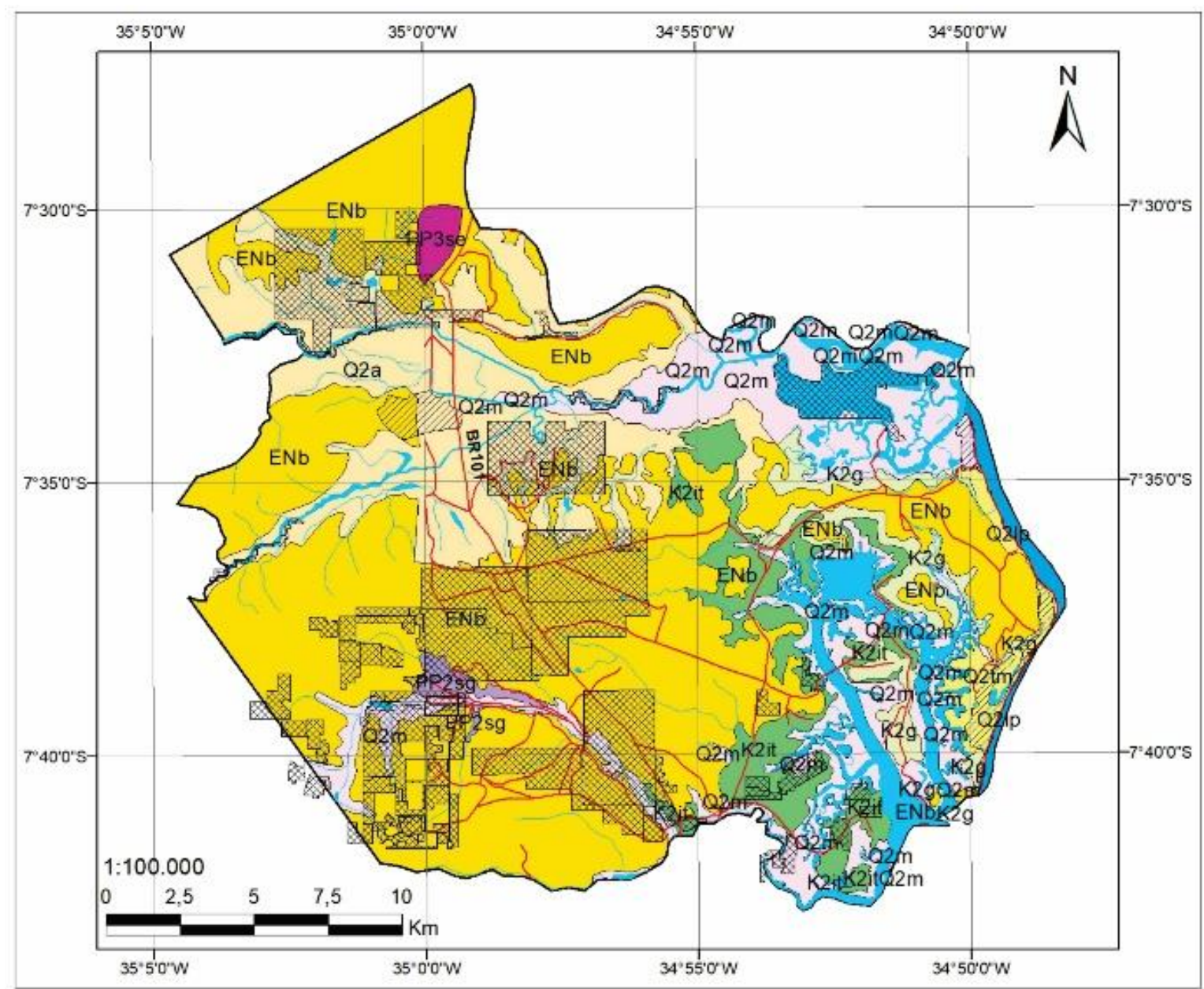

\section{LEGENDA}

\begin{tabular}{|c|c|c|}
\hline Convenções Cartográficas & Unidades Geológicas & \\
\hline \multirow{11}{*}{$\begin{array}{l}\text { Rodovias } \\
\text { Cơregos, riachos e rios } \\
\text { Açude, lago, lagoa e rios } \\
\text { Oceano } \\
\text { Área urbana } \\
\text { Processo ANM - Substáncia areia }\end{array}$} & \multirow{2}{*}{$\begin{array}{l}\text { FANEROZOICO } \\
\text { CENOZOICO } \\
\text { QUATERNȦRIO (Q) }\end{array}$} & $\begin{array}{l}\text { MESOZOICO } \\
\text { CRETACEO (K) }\end{array}$ \\
\hline & & K2g Formaçăo Gramame \\
\hline & Q2m Depósitos de mangue & K2it Formação ltamaracá \\
\hline & Q2a Depósitos aluvionares & K2be Formação Beberibe \\
\hline & Q21p Depósitos litoráneos de praias & \\
\hline & Q2tm Terraços marinhos holocenicos & PALEOPROTEROZOICO (PP) \\
\hline & Q1tm Terraços marinhos pleistocénicos & PP3se Complexo Sertânia \\
\hline & NEÓGENO (N) & PP2sg Complexo Salgadinho \\
\hline & ENb Formaçăo Barreiras & \\
\hline & PALEÓGENO (P) & \\
\hline & E1mf Formação Maria Farinha & \\
\hline
\end{tabular}

Figura 05 - Mapa geológico do município de Goiana evidenciando as diferentes litologias ocorrentes no município. Destacam-se as áreas que possuem titularidade legal (ANM) para o minério areia. Fonte: modificado de CPRM, 1990 e 2017. 
De acordo com os padrões da Associação Brasileira de Normas Técnicas (ABNT), a granulometria predominante é fina a média, concentrando apenas $0,26 \%$ na peneira $\mathrm{N}^{\circ} 08(2,4 \mathrm{~mm})$, e acumulando um percentual superior a $84 \%$ na peneira $\mathrm{N}^{\circ} 100$, com malhas correspondendo a $0,15 \mathrm{~mm}$ (Figura 6). Além disso, os resultados de análises químicas (Tabela 2) identificam um percentual superior a $97 \%$ para sílica $\left(\mathrm{SiO}_{2}\right)$, refletindo a predominância do mineral quartzo e caracterizando o minério como livre de impurezas (argilominerais), devido os demais percentuais analisados menores que $1 \%$.
F1

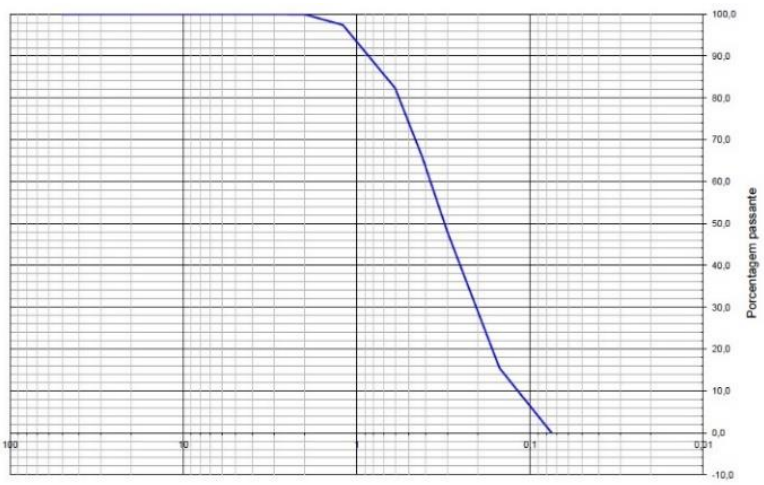

Diametros das particulas mm

F3

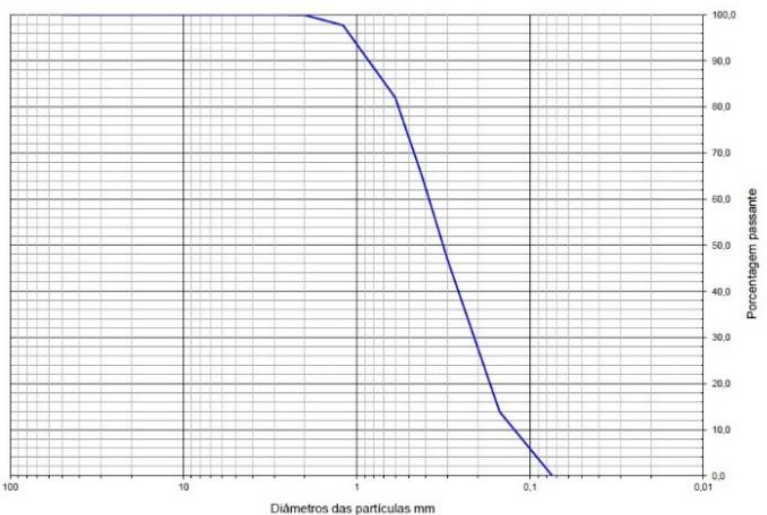

F5

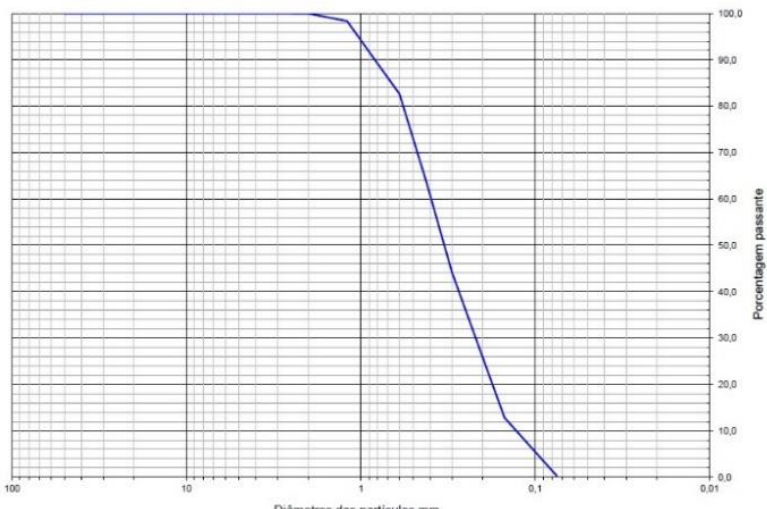

F2

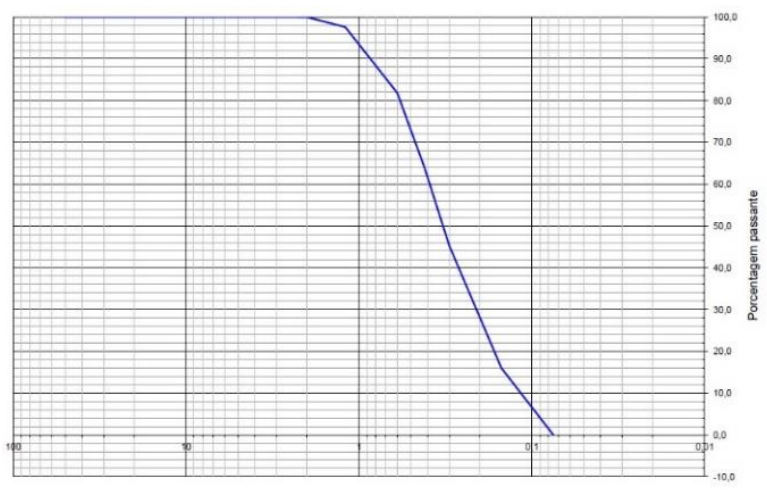

Diâmetros das particulas mm

F4

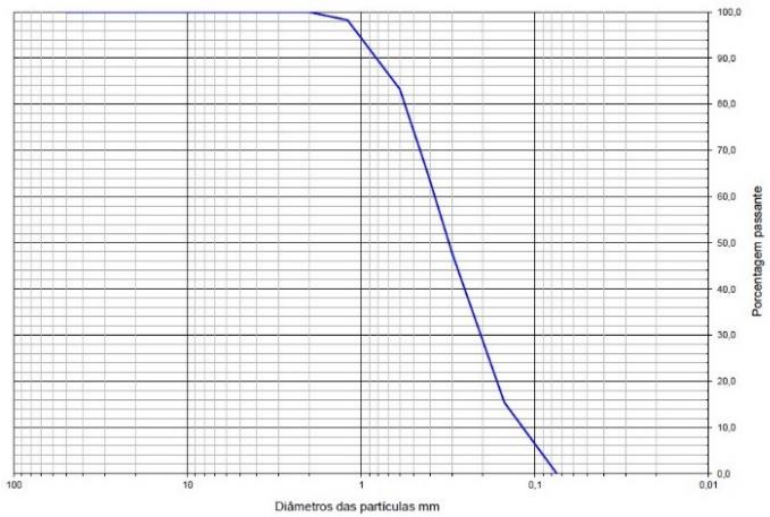

F6

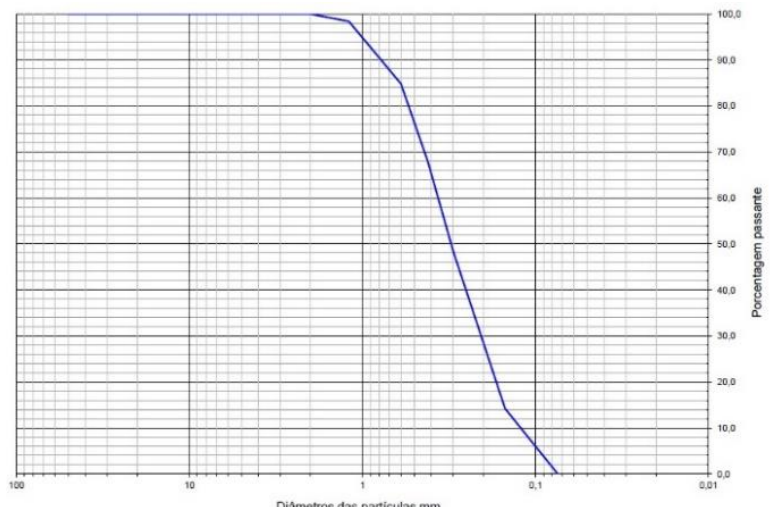

Diametros das particulas mm

Figura 06 - Curvas granulométricas dos intervalos dos respectivos furos estudados de acordo com a NBR 7181/2016: FURO 1 (F1), FURO 2 (F2), FURO 3 (F3), FURO 4 (F4), FURO 5 (F5), FURO 6 (F6). Fonte: autor (2019). 


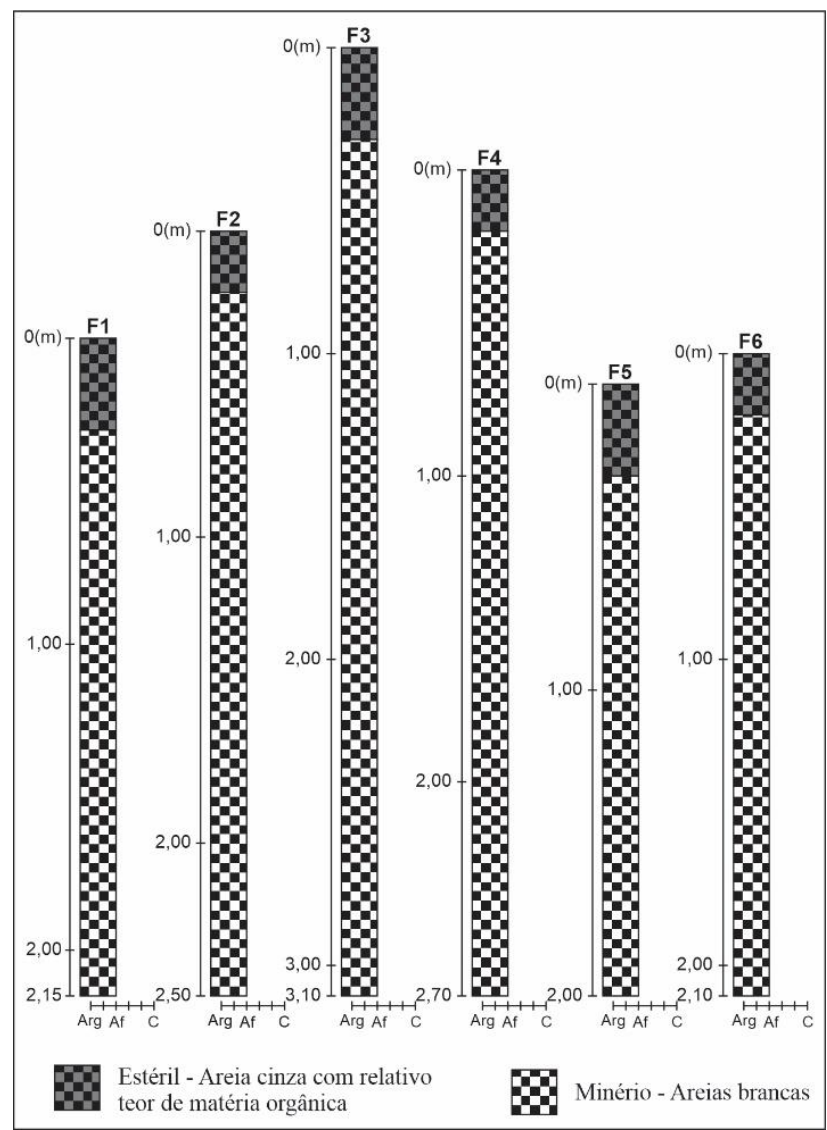

Figura 07 - Ilustrações de perfis de sondagem de algumas perfurações realizadas. Notar a predominância do minério em relação ao estéril. Fonte: autor (2019).

O desenvolvimento do processo de lavra é realizado pelo método a céu aberto, em faixas, que contenham uma menor área possível e com reserva suficiente para atender o consumo de acordo com a produção, a fim de possibilitar, uma recuperação imediata dessa faixa a ser lavrada.

Os materiais estéreis e solo orgânico são depositados em áreas previamente definidas para esse fim, e serão utilizados para a recuperação da área degradada, propiciando uma restauração imediata da área, para possibilitar o cultivo agrícola ou o desenvolvimento da flora, conforme o caso.

Os impactos ambientais a serem gerados com a poeira e o ruído dos equipamentos em operação, trânsito de veículos, desmatamento e possível derramamento de lubrificantes e óleos, são todos mitigados por ocasião do desenvolvimento da lavra, através de programas específicos de controle ambiental.

Como um benefício adicional ao processo de recuperação da área degradada, existe a perspectiva de que, com a remoção da areia, o solo se torne mais apto para a agricultura do que atualmente, pois passará a ser predominantemente argiloso, ao expor a argila do substrato, tornando-se assim mais rico em nutrientes e bem menos ácido.
Tabela 1 - Resultado de análises químicas realizadas para o minério encontrado. Notar o elevado teor de $\mathrm{SiO}_{2}$ em todos os furos e seus respectivos intervalos analisados. Fonte: autor (2019).

\begin{tabular}{|c|c|c|c|c|c|c|}
\hline \multicolumn{7}{|c|}{ Análises Químicas } \\
\hline Furo & F1 & F2 & F3 & F4 & F5 & F6 \\
\hline (1) & 0,30 & 0,20 & 0,30 & 0,20 & 0,30 & 0,20 \\
\hline (2) & 2,15 & 2,50 & 3,10 & 2,70 & 2,00 & 2,10 \\
\hline (3) & 1,85 & 2,30 & 2,80 & 2,50 & 1,70 & 1,90 \\
\hline P.F. & 0,00 & 0,02 & 0,00 & 0,01 & 0,00 & 0,01 \\
\hline $\mathrm{SiO}_{2}$ & 97,37 & 96,52 & 97,64 & 97,81 & 97,41 & 97,59 \\
\hline $\mathbf{A l}_{2} \mathbf{O}_{3}$ & 0,70 & 0,85 & 0,53 & 0,53 & 0,91 & 0,64 \\
\hline $\mathrm{Fe}_{2} \mathrm{O}_{3}$ & 0,69 & 0,77 & 0,72 & 0,68 & 0,65 & 0,68 \\
\hline $\mathrm{CaO}$ & 0,10 & 0,18 & 0,12 & 0,12 & 0,13 & 0,13 \\
\hline MgO & 0,28 & 0,40 & 0,16 & 0,19 & 0,22 & 0,18 \\
\hline $\mathrm{Na}_{2} \mathrm{O}$ & 0,42 & 0,50 & 0,41 & 0,42 & 0,50 & 0,44 \\
\hline $\mathbf{K}_{2} \mathbf{O}$ & 0,00 & 0,00 & 0,00 & 0,00 & 0,00 & 0,00 \\
\hline
\end{tabular}

(1) Profundidade de início do minério no furo (em metros);

(2) Profundidade total do furo (em metros);

(3) Espessura do minério (em metros).

\section{CONSIDERAÇÕES FINAIS}

As atividades de lavra de areia na região estão se intensificando com o aumento da atividade de construção civil, notadamente nos grandes centros urbanos da região, principalmente na Região Metropolitana do Recife.

Considerando todos os aspectos e características do minério a ser produzido, levando em conta a sua viabilidade econômica, estrutura de apoio existente e suas reservas geológicas, a região em questão apresenta uma boa condição comercial para exploração, além da perspectiva de crescimento da construção civil.

A qualidade e a composição granulométrica da areia são consideradas de boa qualidade para a finalidade a que se propõem, razão pela qual os estudos e as explorações vêm se intensificando na região.

\section{REFERÊNCIAS}

Associação Nacional das Entidades de Produtores de Agregados para Construção (ANEPAC). Disponível em: <http://www.anepac.org.br/agregados/areia-e-brita>. Acesso em: 04/03/2019.

Agência Nacional de Mineração (ANM). Disponível em: $<$ http://sigmine.dnpm.gov.br/webmap/>. Acesso em: 15/01/2019.

ABNT NBR 7181/2016. Ensaio de análise granulométrica. 2016.

ALMEIDA, F. F. M.; HASUI, Y.; BRITO NEVES, B. B.; FUCK, R. A. Províncias estruturais brasileiras. In Atas do VII 
Simpósio de Geologia do Nordeste, Campina Grande, 1977. p. 363-391.

ARAI, M.; UESUGUI, N.; ROSSETTI, D. F.; GÓES, A. M. Considerações sobre a idade do Grupo Barreiras no nordeste do Estado do Pará. In Anais do XXXV Congresso Brasileiro de Geologia, v. 2, Belém, 1988. p. 738-752.

ARAI, M.; TRUCKENBRODT, W.; NOGUEIRA, A. C. R., GÓES, A. M.; ROSSETTI, D. F. Novos dados sobre a estratigrafia e ambiente deposicional dos sedimentos Barreiras, NE do Pará. In Boletim de Resumos Expandidos do IV Simpósio de Geologia da Amazônia, Belém, 1994. p. 185-187.

ARAI, M. Dinoflagelados (Dynophiceae) miocênicos do Grupo Barreiras do nordeste do Estado do Pará (Brasil). Revista Universidade de Guarulhos, 2, 98-106, 1997.

BARBOSA, A. G. 1990. Programa Levantamentos Geológicos Básicos do Brasil. Carta Geológica e Carta MetalogenéticoPrevisional da Folha Limoeiro SB.25-Y-C-V. Escala 1:100.000. Recife: CPRM/DNPM, 1990.

BARBOSA, J. A.; SOUZA, E. M.; MABESSONE FILHO, M. F.; NEUMANN, V. H. A estratigrafia da Bacia Paraíba: uma reconsideração. Estudos Geológicos, v. 13, n. 1, 89-108, 2003.

BARboSA, J. A. A Deposição Carbonática na Faixa Costeira das Bacias da Paraíba e da Plataforma de Natal, NE do Brasil: Aspectos Estratigráficos, Geoquímicos $e$ Paleontológicos. Recife, 2007. 278f. Tese (Doutorado em Geociências) - Programa de Pós-Graduação em Geociências, Universidade Federal de Pernambuco, RecifePE, 2007.

BEURLEN, K. Estratigrafia da faixa sedimentar costeira RecifeJoão Pessoa. Boletim da Sociedade Brasileira de Geologia, v. 16, n. $1,43-53,1967 \mathrm{a}$.

BEURLEN, K. Paleontologia da faixa sedimentar costeira Recife-João Pessoa. Boletim da Sociedade Brasileira de Geologia, v. 16, n. 1, 73-79, 1967 b.

BEURLEN, K. A estrutura geológica do Nordeste do Brasil. In Anais XXI Congresso Brasileiro de Geologia. Curitiba, 1967c. 151-158.

BEZERRA, F. H. R.; ROSSETI, D. F.; OLIVEIRA, R. G.; MEDEIROS, W. E.; BRITO NEVES, B. B.; BALSAMO, F.; NOGUEIRA, F. C. C.; DANTAS, E. L.; ANDRADES FILHO, C.; GÓES, A. M. Neotectonic reactivation of shear zones and implications for faulting style and geometry in the continental margin of NE Brazil. Tectonophysics, v. 614, n. 1, 78-90, 2014.

BRITO NEVES, B. B. Regionalização Geotectônica do Precambriano Nordestino. 198f. Tese (Doutorado em Paleontologia e Estratigrafia) - Programa de Pós-Graduação em Geociências, Universidade de São Paulo, São Paulo, 1975 .

BRITO NEVES, B. B.; VAN SCHMUS, W. R.; SANTOS, E. J.; CAMPOS NETO, M. C.; KOZUCH, M. O evento Cariris Velhos na Província Borborema: integração de dados, implicações e perspectivas. Revista Brasileira de Geociências, v. 25, n. 4, 279-296, 1995a.

CORREIA FILHO, O. J.; ALENCAR, M. L.; BARBOSA, J. A.; NEUMANN, V. H. Proposta de Formalização da Formação Tambaba, Eoceno da Bacia Paraíba, NE do Brasil. Estudos Geológicos, v. 25, n. 2, 61-81, 2015.

CPRM - Serviço Geológico do Brasil. Projeto Cadastro de Fontes de Abastecimento por Água Subterrânea, Estado de Pernambuco: Diagnóstico do município de Goiana. Recife, 2005. 21p.

DNPM. Departamento Nacional de Produção Mineral. Sumário Mineral Brasileiro, v. 34, 2014. p. 32-33.

Departamento Nacional de Produção Mineral (DNPM). Sumário Mineral Brasileiro, v. 35, 2015. p. 26-27.

Departamento Nacional de Produção Mineral (DNPM). Sumário Mineral Brasileiro, v. 36, 2016. p. 26-27.

FEIJÓ, F. J. Introdução. Boletim de Geociências da Petrobras, v. 8, n. 1, p. 5-8, 1994.

KEGEL, W. Geologia do fosfato de Pernambuco. Boletim do Departamento Nacional de Produção Mineral, v. 157, 54 p. 1955.

LEITE, F. P. R.; OLIVEIRA, M. E. B.; OLIVEIRA, P. E.; SILVESTRE-CAPELATO, M. S.; ARAI, M.; TRUCKENBRODT, W. Palinofloras miocênicas da Formação Pirabas e Grupo Barreiras, na Região Bragantina, Estado do Pará, Brasil. Revista Universidade de Guarulhos, 2, 128-140, 1997a.

LEITE, F. P. R.; OLIVEIRA, M. E. B.; ARAI, M.; TRUCKENBRODT, W. Palinoestratigrafia da Formação Pirabas e Grupo Barreiras, Mioceno do nordeste do estado do Pará. Revista Universidade de Guarulhos, 2, 141-147, 1997b.

LIMA, F. H. O.; KOUTSOUKOS, E. A. M. Calcareous nannofossil biostratigraphy in the Maastrichtian of the Pernambuco-Paraíba Basin, NE Brazil. In VI Simpósio sobre o Cretáceo do Brasil, Boletim de resumos, 2002. p. 279-284.

LIMA FILHO, M. F.; MONTEIRO, A. B.; SOUZA, E. M. Carbonate sections of the Paraiba and Pernambuco Basins, Northeastern Brazil: Implications for the late stages of opening of Southern Atlantic Ocean. In 15th International Sedimentological Congress, v. 1, 1998. p. 504-505.

MAURY, J. M; ALHEIROS, M. M. Origem da Bacia Sedimentar Costeira Pernambuco/Paraíba. Revista Brasileira de Geociências, v. 18, n. 4, 476-482, 1988. 
MAURY, C. J. O Cretáceo da Parahyba do Norte. Monografia do Serviço Geológico Mineral, v. 8, 1930. 305p.

MOURA, C. R. Ostracodes da transição entre as formações Itamaracá e Gramame Bacia Paraíba: Taxonomia, implicações paleoecológicas, paleoambientais $e$ bioestratigráficas. Recife, 2007. 101f. Dissertação (Mestrado em Geociências). Programa de Pós-Graduação em Geociências, Universidade Federal de Pernambuco, Recife-PE, 2007.

MUNIZ, G. C. B. Novos moluscos da Formação Gramame, Cretáceo Superior dos Estados da Paraíba e de Pernambuco, Nordeste do Brasil. Departamento de Geologia, Universidade Federal de Pernambuco. Publicação Especial 1, 1993. 202 p.

NEVES, S. P., Bruguier, O., Vauchez, A., Bosch, D., Silva, J. M. R., Mariano, G. Timing of crust formation, deposition of supracrustal sequences, and Transamazonian and Brasiliano metamorphism in the East Pernambuco belt (Borborema Province, NE Brazil): implications for western Gondwana assembly. Precambrian Research, v. 149, n. 3, 197-216, 2006.

OLIVEIRA, R. G.; sousa, E. J. Seção geológica-geofísica e inferências geotectônicas na porção centro-sul da Província Borborema. In III Congresso Internacional da Sociedade Brasileira de Geofísica, Resumos Expandidos, Rio de Janeiro, 1993. p. 643-747.

QUARESMA, L. F. Relatório Técnico 31: Perfil de areia para a construção civil. 2009. 33 p.

ROSSETI, D. F. Evolução sedimentar miocênica nos estados do Pará e Maranhão. Geologia USP - Série Científica, v. 6, n. 2, 7-18, 2006.

SANTOS, E. J. O complexo granítico Lagoa das Pedras: acresção e colisão na região de Floresta (Pernambuco), Província Borborema. São Paulo, 1995. 219f. Tese (Doutorado em Geociências). Programa de Pós-Graduação em Geociências, Universidade de São Paulo, São Paulo-SP, 1995.

SANTOS, E. J. Ensaio preliminar sobre terrenos e tectônica acrescionária na Província Borborema. In Anais do XXXIX Congresso Brasileiro de Geologia, Salvador, 1996. p. 47-50.

SOUZA, E. M. Levantamento Radiométrico das Unidades Estratigráficas da Bacia Paraíba. Recife, 1998. 152f. Dissertação (Mestrado em Geociências). Programa de PósGraduação em Geociências, Universidade Federal de Pernambuco, Recife-PE, 1998.

SOUZA, E. M. Estratigrafia da Sequência Clástica Inferior (Andares Coniaciano-Maastrichtiano Inferior) da Bacia da Paraíba e Suas Implicações Paleogeográficas. Recife, 2006. 350f. Tese (Doutorado em Geociências). Programa de PósGraduação em Geociências, Universidade Federal de Pernambuco, Recife-PE, 2006.
TORRES, F. S. M.; PFALTZGRAFF, P. A. S. Geodiversidade do Estado de Pernambuco. Recife: CPRM, 2014. 282 p.

TINOCO, I. M. Foraminíferos e a Passagem entre o Cretáceo e o Terciário em Pernambuco. São Paulo, 1971. 147f. Tese (Doutorado em Geociências). Programa de Pós-Graduação em Geociências, Universidade de São Paulo, São Paulo-SP, 1971.

VALENÇA, L. M. M.; SOUZA, N. G. A. 2017. Programa Geologia do Brasil - PGB. Geologia e Recursos Minerais da Folha Itamaracá SB.25-Y-C-VI. Escala 1:100.000. Recife: CPRM/UFPE, 2017.

Recebido em: 08/05/2020

Aceito para publicação em: 01/03/2021 